\title{
The neutrophil serine protease PR3 induces shape change of platelets via the Rho/Rho kinase and $\mathrm{Ca} 2+$ signaling pathways
}

Xiang Peng, Sofia Ramström, Tino Kurz, Magnus Grenegård and Mårten Segelmark

\author{
Linköping University Post Print
}

Tweet

N.B.: When citing this work, cite the original article.

Original Publication:

Xiang Peng, Sofia Ramström, Tino Kurz, Magnus Grenegård and Mårten Segelmark, The neutrophil serine protease PR3 induces shape change of platelets via the Rho/Rho kinase and Ca2+ signaling pathways, 2014, Thrombosis Research, (134), 2, 418-425.

http://dx.doi.org/10.1016/j.thromres.2014.06.001

Copyright: Elsevier

http://www.elsevier.com/

Postprint available at: Linköping University Electronic Press

http://urn.kb.se/resolve?urn=urn:nbn:se:liu:diva-111292 


\title{
The neutrophil serine protease PR3 induces shape change of platelets via the $\mathrm{Rho} / \mathrm{Rho}$ kinase and $\mathrm{Ca}^{2+}$ signaling pathways
}

\author{
Xiang Peng ${ }^{1,2}, *$, Sofia Ramström ${ }^{3}$, Tino Kurz ${ }^{2}$, Magnus Grenegård ${ }^{2,4}$, Mårten Segelmark ${ }^{2}$ \\ ${ }^{1}$ Department of Nephrology, Qingyuan City Hospital of Jinan University, Guangdong, China. \\ ${ }^{2}$ Department of Medical and Health Sciences, Linköping University, Linköping, Sweden * \\ ${ }^{3}$ Department of Experimental and Clinical Medicine, Linköping University, Linköping, Sweden \\ ${ }^{4}$ School of Medicine, Örebro University, Örebro, Sweden
}

* Corresponding author: Xiang Peng, Department of Medical and Health Sciences, Linköping University, SE-58185 Linköping, Sweden. Tel: +46 735834361; fax: +46 13149106. Email address: peng.xiang@liu.se. Department of Nephrology, Qingyuan City Hospital of Jinan University, Guangdong, China.

$\star$ All experiments were performed at the Department of Medical and Health Sciences, Linköping University, Sweden.

Part of the data in this manuscript was presented in abstract form and as an oral presentation at the $16^{\text {th }}$ International Vasculitis \& ANCA Workshop in Paris on April 15, 2013. 


\section{Abstract}

Introduction: Proteinase 3 (PR3) is released from neutrophil azurophilic granules and exerts complex effects on the inflammatory process. PR3 catalyzes the degradation of a number of macromolecules, but the consequences on blood cells are less well defined. In the present study, the effect of PR3 on human platelets was thoroughly investigated.

Methods: The experiments were performed on washed platelets freshly isolated from blood donated by healthy human volunteers. Platelets shape change and aggregation was measured on a Chrono-Log aggregometer. The phosphorylated form of MYPT1 was visualized by immunostaining. Platelet activation was further evaluated by flow cytometry.

Results: PR3 induced platelet shape change but not aggregation. Flow cytometry analysis of fibrinogen binding to platelets confirmed that PR3 could not activate the RGD recognition integrin GPIIb/IIla. Furthermore, Fura-2 measurement and immuno-blotting analysis, respectively, revealed that PR3 stimulated small intracellular $\mathrm{Ca}^{2+}$ mobilization and Thr696-specific phosphorylation of the myosin phosphatase target subunit 1 (MYPT1). Separate treatment of platelets with the Rho/Rho kinase inhibitor Y-27632 and the intracellular $\mathrm{Ca}^{2+}$ chelator BAPTA/AM reduced the shape change induced by PR3 whereas concurrent treatment completely inhibited it. Conclusion: The data shows that the neutrophil protease PR3 is a direct modulator of human platelets and causes shape change through activation of the Rho/Rho kinase and $\mathrm{Ca}^{2+}$ signaling pathways. This finding highlights an additional mechanism in the complex interplay between neutrophils and platelets. 


\section{Keywords}

ANCA-associated vasculitis, Proteinase PR3, Platelet shape change, Rho/Rho kinase signaling pathway, $\mathrm{Ca}^{2+}$ signaling pathway

\section{Abbreviations}

AAV, ANCA-associated vasculitis; ACD, acid-citrate dextrose; ANCA, Anti-Neutrophil Cytoplasmic antibodies; CG, cathepsin G; GPA, Granulomatosis with polyangiitis; HLE, Human Leukocyte Elastase; KRG, Krebs-Ringer glucose; MYPT1, myosin phosphatase target subunit 1; PAR1, protease-activated receptor 1; PR3, Proteinase 3; PRP, platelet-rich plasma; TXA2, thromboxane $A_{2}$; VWF, von Willebrand factor. 


\section{Introduction}

Beyond functions in haemostasis and thrombosis, platelets are considered to play an important role in inflammation by, for instance, modulating the functions of neutrophils $[1,2]$. The cross-talk between platelets and neutrophils may have profound consequences in several pathophysiological situations, such as sepsis and systemic autoimmune syndromes. In severe sepsis, platelets are able to trigger the formation of neutrophil extracellular traps (NETs), which bind and clear pathogens [3]. ANCA-associated vasculitis (AAV) encompasses a variety of autoimmune diseases characterized by the presence of Anti-Neutrophil Cytoplasmic Antibodies (ANCA) associated with small vessel damage $[4,5]$. Platelets and leukocytes co-localize and interact at sites of vessel injury, haemorrhage, thrombosis and inflammation. Neutrophils engaged by adhering platelets undergo activation, NET-osis and depletion of the content of their granules [6].

The serine protease PR3 was identified as a major target autoantigen for ANCA in Granulomatosis with polyangiitis (GPA, earlier called Wegener's granulomatosis). PR3 is a versatile protein produced by neutrophils and monocytes belonging to a large family of serine proteases including better known members such as trypsin, thrombin, Human Leukocyte Elastase (HLE) and cathepsin G (CG) [7]. After being synthesized as a prepro-enzyme, PR3 is processed into a mature form consisting of 222 amino acids in four consecutive steps. Together with HLE and CG, mature PR3 is stored in neutrophil azurophilic granules. They all are secreted extracellularly upon neutrophil activation [8], but only PR3 is constitutively expressed on the plasma membranes of a subpopulation of resting neutrophils $[9,10]$. The levels of plasma PR3, proPR3 and neutrophil 
membrane PR3 are all elevated in patients with sepsis and AAV [10]. PR3 can enzymatically degrade the major macromolecules of extracellular matrix [8]. It also acts as an immunomodulator by cleaving cytokine precursors into their active form and by degrading active cytokines or cytokine receptors. Reported examples include IL-8, IL-1 $\beta$, TNF $\alpha$ and IL-6 [7]. Furthermore, proPR3 is a hematopoietic feed-back regulator of granulopoiesis [11] and PR3 has been shown to enter endothelial cells resulting in the induction of apoptosis [12].

A potential effect of PR3 on platelets has not been studied in detail. In a report from 1994, Renesto, et al. did not find any direct effect of PR3 on platelets, but a dose-dependent augmenting effect of PR3 on CG-induced platelet aggregation and serotonin release, especially at high concentrations $(5-25 \mu \mathrm{g} / \mathrm{ml}=170-860 \mathrm{nM})$ [13]. In a later publication, the same group showed that incubation with PR3 $(600 \mathrm{nM})$ reduced the number of thrombin receptors on the platelet surface and the rise in intracellular calcium in platelets induced by thrombin ( $5 \mathrm{nM})$, but not by a protease-activated receptor 1 (PAR1)-activating peptide (TRAP 42-55, $6.25 \mu \mathrm{M}$ ), and showed no effect on calcium levels by PR3 alone [14]. They also demonstrated a putative cleavage site in PAR1 for PR3, Val ${ }^{72}-\mathrm{Ser}^{73}$. The aim of the present investigation was to determine whether PR3 has a direct effect on human blood platelets. Specifically, the purpose was to elucidate functional response(s) induced by PR3 and to discern the underlying intracellular signaling pathway(s).

\section{Materials and Methods}

\section{Reagents}

Y-27632, $\alpha$-thrombin from human plasma, apyrase (Grade III), Fura-2/AM (fura 2 acetoxymethyl 
ester), acetylsalicylic acid, albumin from bovine serum (BSA), ADP, adrenaline and buffer chemicals were all obtained from Sigma-Aldrich (St Louis, MO, USA). Purified human Proteinase-3 (PR3) was kindly provided by Wieslab AB (Malmö, Sweden). PP2, PP3 and BAPTA/AM was from Calbiochem (La Jolla, CA, USA). The PAR1 thrombin-receptor-activating peptide (PAR1-AP, amino acid sequence SFLLRN) [15] and the PAR4 thrombin receptor activating peptide (PAR4-AP, amino acid sequence AYPGKF) [16] were synthesized by JPT (Berlin, Germany). The PAR1 antagonist SCH79797 dihydrochloride (N3-Cyclopropyl-7-[4-(1methylethyl) phenyl] methyl-7H-pyrrolo [3,2-f]quinazoline-1,3-diamine dihydrochloride) was obtained from Tocris Cookson Ltd. (Bristol, UK). Secretory leukocyte protease inhibitor (SLPI) was from R\&D Systems (Minneapolis, USA). Specific synthetic PR3 inhibitor Ac-PYDA-Pcl (PYDA) and specific PR3 substrate Abz-VADnorVADYQ-EDDnp [17] were kindly provided by Dr. Brice Korkmaz (Centre d' Etude des Pathologies Respiratoires, INSERM U-1100/EA-6305, Tours, France). Anti-phospho-MYPT1 (Thr696) was from Millipore (Billerica, MA, USA). Secondary anti-rabbit-HRP antibody was from Santa Cruz Biotechnology Inc. (California, USA). ECL plus solution was from Perkin Elmer, Inc. (Waltham, MA, USA). Fluorescein (FITC)-conjugated chicken antibodies towards human fibrinogen were from Diapensia HB (Linköping, Sweden). APC-conjugated monoclonal mouse antibodies towards human P-selectin (CD62P, clone AK4) were from BD Biosciences (San Jose, USA) and phycoerythrin (PE)-conjugated monoclonal mouse antibodies towards human GPIb (CD42b, clone AN51) were from Dako AS (Glostrup, Denmark).

\section{Isolation of human platelets}

Platelets were isolated from heparinised blood obtained from the blood bank at Linköping 
University Hospital. (Delay between drawing of blood and start of platelet separation was always less than 1 hour). One part acid-citrate dextrose (ACD) solution (85 mM Na-citrate, $71 \mathrm{mM}$ citric acid, and $111 \mathrm{mM}$ glucose) and five parts blood were mixed and centrifuged at $150 \mathrm{~g}$ for 20 min to obtain platelet-rich plasma (PRP). The PRP was treated with $100 \mu \mathrm{M}$ acetylsalicylic acid and $0.5 \mathrm{U} / \mathrm{ml}$ apyrase to prevent activation of platelets by thromboxane $A_{2}\left(T_{X} A_{2}\right)$ and ADP/ATP during the isolation procedure. The platelets were isolated by centrifugation at $520 \mathrm{~g}$ for $25 \mathrm{~min}$ and then resuspended in Krebs-Ringer glucose (KRG) buffer (120 mM NaCl, $4.9 \mathrm{mM} \mathrm{KCl,} 1.2 \mathrm{mM}$ $\mathrm{MgSO}_{4}, 1.7 \mathrm{mM} \mathrm{KH}_{2} \mathrm{PO}_{4}, 8.3 \mathrm{mM} \mathrm{Na}_{2} \mathrm{HPO}_{4}$, and $10 \mathrm{mM}$ glucose; $\mathrm{pH} 7.3$ ) supplemented with 1 $\mathrm{U} / \mathrm{ml}$ apyrase.

\section{Measurement of platelet shape change and aggregation}

A Chrono-Log aggregometer (Chrono-Log Corporation, Pennsylvania, USA) was used to measure aggregation responses in suspended platelets $\left(2.5 \times 10^{8} / \mathrm{ml}\right)$ under constant stirring (800 rpm). The extracellular calcium concentration was adjusted to $1 \mathrm{mM}$ in the samples, which were subsequently allowed to equilibrate at $37^{\circ} \mathrm{C}$ before adding PR3 $(0.1-3.0 \mu \mathrm{g} / \mathrm{ml}=3.5-100 \mathrm{nM})$. The Rho-kinase inhibitors Y-27632 and the intracellular $\mathrm{Ca}^{2+}$ chelator BAPTA/AM were added 5 min before PR3. Serum and PYDA were incubated for 30 min at $37^{\circ} \mathrm{C}$ with PR3 prior to the addition to aliquots of platelets suspensions. Adrenaline and PAR1 antagonist SCH79797 were added 2 min before PR3. PR3 was added $1 \mathrm{~min}$ before ADP but for these experiments, isolated platelets were prepared as described before but resuspended in KRG buffer without apyrase. Changes in light transmission in response to PR3 were followed and recorded over time. 


\section{Immunoblotting and measurement of protein phosphorylation}

PR3 $(0.6 \mu \mathrm{g} / \mathrm{ml})$ was added to aliquots of platelet suspensions $\left(2.5 \times 10^{8}\right.$ platelets $\left./ \mathrm{ml}\right)$ incubated in aggregometer cuvettes $\left(37^{\circ} \mathrm{C} ; 800 \mathrm{rpm}\right)$, and the reaction was stopped after 10 seconds by adding an equal volume of SDS-PAGE sample buffer (Bio-Rad, Hercules, CA, USA). The samples were immediately transferred to Eppendorf tubes and heated to $95^{\circ} \mathrm{C}$ for $5 \mathrm{~min}$. Proteins were separated on a $10 \%$ Tris- $\mathrm{HCl}$ gel from Bio-Rad (Hercules, CA, USA) and then transferred by electroblotting to an Immobilon-P membrane from Millipore (Billerica, MA, USA), which was subsequently blocked with $5 \%$ (wt/vol) BSA solution (albumin from bovine serum diluted in $1 \times$ TBST buffer). The phosphorylated form of MYPT1 was visualized by immunostaining. Anti-phospho-MYPT1 (Thr696) and the secondary anti-rabbit-HRP antibody were used at a concentration of 1:2,000. The membranes were developed with ECL plus solution, and the chemiluminescence was detected using a Fuji LAS-1000 system from Fuji Photo Film (Tokyo, Japan). Densitometric analysis of the protein bands was done with Image Gauge 4.0 software from Fuji Photo Film (Tokyo, Japan).

\section{Measurement of changes in cytosolic $\mathrm{Ca}^{2+}$}

Platelets were loaded with Fura-2/AM by incubating platelet-rich plasma with $3 \mu \mathrm{M}$ Fura-2/AM for $45 \mathrm{~min}$ at room temperature and were subsequently isolated as described above. Platelets were pre-incubated and stimulated as indicated at $37^{\circ} \mathrm{C}$ and fluorescence was recorded using a Hitachi F-7000 spectrofluorometer at $510 \mathrm{~nm}$ with simultaneous excitation at $340 \mathrm{~nm}$ and $380 \mathrm{~nm}$. The cytosolic calcium concentration $\left[\mathrm{Ca}^{2+}\right]_{i}$ was expressed as a fluorescence ratio $(340 / 380 \mathrm{~nm})$. 


\section{Flow cytometry measurement of platelet activation}

Platelet activation was evaluated by flow cytometry using platelet-bound fibrinogen as a marker for fibrinogen receptor GPIIb/IIla transformation into its active conformation [18] and P-selectin expression as a marker for platelet $\alpha$-granule release. Isolated platelets prepared as described before and resuspended in $\mathrm{KRG}$ buffer with $1 \mathrm{mM} \mathrm{CaCl}_{2}$ but without apyrase were pre-incubated with PR3 for $10 \mathrm{~min}$ at room temperature in the dark (final concentrations 0.6 or $3 \mu \mathrm{g} / \mathrm{ml}$ ). Control samples were also incubated with buffers with different concentrations of Triton X-100, corresponding to the concentrations in the different PR3 preparations tested. Five $\mu$ l of platelet suspension $\left(2.5 \times 10^{8} / \mathrm{ml}\right)$ was transferred to plastic tubes containing anti-fibrinogen-FITC (final concentration $2 \mu \mathrm{g} / \mathrm{ml}$ ), anti-P-selectin-APC (final concentration $0.02 \mu \mathrm{g} / \mathrm{ml}$ ), anti-GPlb-PE (final concentration $1.3 \mu \mathrm{g} / \mathrm{ml}$ ), platelet agonists (final concentrations; PAR1-AP: 2.5 , 10 or $30 \mu \mathrm{M}$, PAR4-AP: 10,50 or $200 \mu \mathrm{M}$, thrombin: $0.05,0.1,0.2,0.5$ or $2 \mathrm{U} / \mathrm{ml}$ ) and HEPES buffer to a final volume of $70 \mu \mathrm{l}$. For the negative control sample, an isotype control antibody (IgG $\left.{ }_{1}-A P C\right)$ with corresponding fluorescence replaced the anti-P-selectin antibody and the buffer was supplemented with 10 mM EDTA to prevent binding of the anti-fibrinogen antibody. After exactly 10 min incubation in the dark, the reaction was stopped by addition of 2 ml HEPES buffer (137 $\mathrm{mM} \mathrm{NaCl}, 2.7 \mathrm{mM} \mathrm{KCl}, 1 \mathrm{mM} \mathrm{MgCl}$, $5.6 \mathrm{mM}$ glucose, $1 \mathrm{~g} / \mathrm{l}$ bovine serum albumin and $20 \mathrm{mM}$ HEPES, pH 7.40). All steps were performed at room temperature and with only gentle mixing of the samples to avoid contact between platelets. For flow cytometry analysis, platelets were identified by their forward scatter and anti-GPIb-PE fluorescence. Platelet particles were analysed in histograms for FITC and APC fluorescence. An analytical marker was set in the histograms to divide the platelets in the negative control sample into two fractions, one that contained $98-99 \%$ 
of the platelets and the other containing the brightest $1-2 \%$ of the platelets. Platelets with fluorescence intensity higher than the marker were identified as fibrinogen binding (FITC-positive) or P-selectin expressing (APC-positive). All samples were run in duplicate.

\section{Statistical methods}

Statistical analysis was done using SPSS 16.0 for Windows software (IBM Corporation, New York, USA). Significant differences were calculated either by applying paired Student's t-test or analysis of variance (ANOVA) and Dunnett's multiple comparison as post-hoc test when applicable ( $\star p<$ $0.05, \star \star \mathrm{p}<0.01)$. Results are presented as means \pm standard error of the mean (SEM).

\section{Results}

\section{PR3 induces a rapid shape change but no subsequent aggregation in platelets}

Addition of PR3 $(0-3.0 \mu \mathrm{g} / \mathrm{ml}=0-100 \mathrm{nM})$ to isolated human platelets induced an immediate and dose-dependent decrease in light transmission, usually interpreted as platelet shape change (Fig. $1 \mathrm{~A}$ and $\mathrm{B}$ ). As compared to the response to $0.2 \mathrm{U} / \mathrm{ml}$ thrombin shown as the last trace, the initial phase of platelet activation induced by PR3 was not followed by the steep and rapid increase in light transmission indicating platelet aggregation. In control experiments, platelets were exposed to PR3 for up to 20 minutes or aliquots of platelet suspensions were supplemented with fibrinogen $(100 \mu \mathrm{g} / \mathrm{ml})$ without causing aggregation (data not shown). Pre-incubation with adrenaline $(10 \mu \mathrm{M})$ enhanced the magnitude of the decrease in light transmission induced by PR3, but the adrenaline/PR3 combination did not cause aggregation (Figure 1C). Pre-incubation with PAR1 antagonist SCH79797 (10 $\mu \mathrm{M})$ showed no influence on the shape change induced by PR3 
(data not shown, $n=3$ ). Also, PR3 showed no enhancing effect on ADP-induced platelet aggregation in platelets resuspended in KRG buffer without apyrase (data not shown, n=3).

\section{PR3 does not affect P-selectin expression or fibrinogen binding in platelets}

Platelet activation by PR3 induced a rapid decrease in light transmission but no aggregation as detected by light transmission aggregometry. To explore possible mechanisms by which PR3 could affect platelets, we used flow cytometry to study whether PR3 could affect platelet activation induced by thrombin or specific PAR1- or PAR4-activating peptides (SFLLRN and AYPGKF, respectively). Release of alpha granule contents and activation of the fibrinogen receptor was studied using flow cytometry by measuring expression of P-selectin and binding of fibrinogen to the platelets, respectively. In this system the P-selectin expression and fibrinogen binding was not altered by platelet incubation with Triton $\mathrm{X}-100$ in the concentrations present in the PR3 suspensions, showing that Triton X-100 did not have any measurable effect on its own (data not shown). Isolated platelets were then incubated with PR3 in two different doses $(0.6$ and $3 \mu \mathrm{g} / \mathrm{ml})$ and their activation in response to different platelet agonists was determined. Pre-incubation with PR3 showed no significant effects on platelet P-selectin expression or binding of fibrinogen. It did not change the spontaneous activation response in samples where only buffer was added for activation, nor did it change the activation in response to PAR1-activating peptide (SFLLRN: 2.5, 10 or $30 \mu \mathrm{M}$ ), PAR4-activating peptide (AYPGKF:10, 50 or $200 \mu \mathrm{M})$ or thrombin $(0.05,0.1,0.2$, 0.5 or $2 \mathrm{U} / \mathrm{ml}$ ) at either low or high concentrations. Figures $2 \mathrm{~A}$ and $\mathrm{B}$ show the results with the intermediate doses of platelet agonists, but no effects by PR3 were observed at any of the 
concentrations (data not shown).

PR3-induced shape change in platelets is dependent on PR3 enzymatic activity

Most effects of PR3 are dependent on its enzymatic activity. To discern whether this was the case with platelet shape changes, purified PR3 was incubated with serum (1:1) or PYDA (a synthetic low molecular weight PR3-specific inhibitor, $1 \mu \mathrm{M}$ ) for 30 minutes at $37^{\circ} \mathrm{C}$ prior to its addition to the platelets (Fig. 3A). Pre-incubation with serum diminished the shape change and PYDA pre-incubation showed an almost complete prevention. The purity of the PR3 preparations are routinely tested during purification by ELISA using antibodies against bactericidal/permeability-increasing protein, azurocidin, CG, lactoferrin, elastase and myeloperoxidase. All gave negative results for the batches used in our experiments. Furthermore, control experiments were conducted using a colorimetric assay to measure the enzymatic activity of PR3. The results showed that PYDA $(1 \mu \mathrm{M})$ but not SLPI $(10 \mu \mathrm{g} / \mathrm{ml})$ could inhibit the enzymatic activity of our PR3 preparation (data not shown). SLPI is known to inhibit CG[19] and HLE but not PR3 [20]. Hence, our PR3 preparation had no enzymatic impurity that could account for the activity attributed to PR3. However, the stock solution of PR3 contains $0.1 \%$ Triton X-100, a detergent used to block adhesion of PR3 to surfaces during storage. We found that Triton X-100 in higher concentrations also could have some effect on light transmission in platelet suspensions. However, when PR3 was diluted to low concentrations $(0.6-1 \mu \mathrm{g} / \mathrm{ml})$, we still observed changes in light transmission, but the corresponding concentrations of Triton X-100 $\left(6.7 \times 10^{-5} \%\right)$ alone left the platelets unaffected. We also tested a Triton X-100-free PR3 batch and could confirm the same biological effect (data not shown). 
PR3-induced platelet shape change relies on activation of Rho-kinase and calcium signaling cascades

Fura-2-measurements revealed that PR3 induced a small but distinct elevation of the intracellular calcium concentration in platelets (a typical curve is shown as an insert in Fig. 3C). Furthermore, pre-incubation with the intracellular calcium chelator BAPTA/AM $(20 \mu M)$ partly reduced the change in light transmission induced by PR3 (Fig. 3B). Pre-incubation with the Rho-kinase inhibitor Y-27632 (20 $\mu \mathrm{M})$ also reduced the PR3-provoked responses (Fig. 3B and C). When platelets were pre-exposed to both BAPTA/AM and Y-27632, the PR3-induced platelet response was completely abolished (Fig. 3B). Inhibition of Src family kinases by PP2 showed no effect on the PR3-induced shape change ( $n=5$, data not shown).

Shape change mediated by the Rho/Rho-kinase pathway involves the inhibition of myosin phosphates through Thr696-specific phosphorylation of MYPT1. We analysed phosphorylation of MYPT1 by western blotting using an antibody specific for MYPT1 phosphorylated at the Thr696 residue. The result revealed that PR3 induced a rapid, Y-27632-sensitive increase in Thr696 phosphorylation, which according to densitometric analysis, was comparable to the rise in Thr696 phosphorylation provoked by an intermediate dose of thrombin $(0.2 \mathrm{U} / \mathrm{ml})$. Furthermore, PR3-induced Thr696 phosphorylation was PYDA-sensitive, confirming that this effect results from the enzymatic activity of PR3 (Fig. 3D).

\section{Discussion}


This study provides evidence for a role of the neutrophil protease PR3 in modulating a specific function of human platelets. Specifically, we found that PR3 induced a rapid decrease in light transmission in suspensions of isolated human platelets, which is usually considered as an indication of early activation and shape change.

Activation of platelets is mainly correlated to aggregation and the formation of the primary hemostatic plug. However, adhesion, complex shape change, extensive secretion as well as postaggregatory events (e.g. induction of clot retraction) are normal components of platelet physiology. In our study we present evidence that PR3 dose-dependently induced platelet shape change without other manifestations of platelet activation. The platelets were pre-treated with aspirin and apyrase, thus the observed shape change was a direct consequence of PR3 and not caused by secondary autocrine feedback activation from TXA 2 or ADP. Light transmission as well as flow cytometry measurements revealed that PR3 did not induce activation of the fibrinogen (RGD)-binding integrin GPIIb/IIla. This implies that PR3 alone cannot induce platelet aggregation. Similar to our findings, many previous studies have shown that certain activators, independent of dose, only induce increased adhesion/shape change [21-24]. This diverse group of endogenous molecules includes adrenaline, ATP, serotonin, lysophosphatidic acid, alpha1-acid glycoprotein, and many others and they are often referred to as "weak activators", "potentiating/priming stimuli" and "positive modulators" [25]. Based on the present findings, we propose that PR3 should be considered a direct, positive modulator of human blood platelets.

Elucidating the physiological role(s) of PR3-induced platelet activation is beyond the scope of the present investigation. There is a large body of evidence that positive modulators, such as adrenaline, facilitate for secretion and aggregation when platelets are subsequently exposed to 
strong activators like thrombin, ADP and collagen $[26,27]$. However, PR3 was not shown to alter activation of the fibrinogen receptor in response to thrombin, PAR1- or PAR4-activating peptides at any concentrations, nor did it change the magnitude of ADP-induced aggregation (in the absence of apyrase). Based on these findings, we conclude that PR3 is not a priming stimulus of platelet secretion and aggregation. PR3 as well as other proteases are secreted upon neutrophil activation [28], but only PR3 is constitutively expressed on the plasma membranes of a subpopulation of resting neutrophils [9]. Consequently, it is possible that PR3 plays a role in the reciprocal cross-talk between neutrophils and platelets. If membrane-expressed PR3 induces adhesion and discrete activation of platelets to the surface of neutrophils remains to be determined.

The intracellular signal transduction pathways leading to platelet shape change include $\mathrm{Ca}^{2+}$ mobilization and Rho/Rho-kinase activation $[29,30]$. The latter signaling pathway causes specific Thr696 phosphorylation of MYPT1. We found that PR3 induced a minor $\mathrm{Ca}^{2+}$ response and a marked increase in Thr696 phosphorylation of MYPT1. Furthermore, inhibition of Rho-kinase and $\mathrm{Ca}^{2+}$ mobilization abolished the shape change induced by PR3. Therefore, we conclude that PR3 stimulates shape change of human platelets through activation of the Rho/Rho kinase and $\mathrm{Ca}^{2+}$ signaling pathways. It is well established that adrenaline enhances platelet activation by other, more efficient activators [27]. We found that adrenaline reinforced platelet shape change by PR3 but this was not followed by aggregation. Consequently, the signaling power attributable to PR3 (i.e. Rho activation and minimal $\mathrm{Ca}^{2+}$ mobilization) is not linked to formation of platelet aggregates. Interestingly, we recently showed that the acute-phase reactant alpha1-acid glycoprotein caused platelet shape change, but not secretion or aggregation, via 
activation of the same intracellular signaling pathways [31]. This may imply that acute inflammation is associated with priming of platelets via molecules such as PR3 and alpha1-acid glycoprotein. Such priming will not cause aggregation but may potentially lead to increased platelet/neutrophil adhesion interactions with other cells and/or improved responsiveness of platelets towards other activators. This needs to be further tested in future studies.

Only a few previous studies have examined the effect of PR3 on human platelets. Renesto et al. reported that high doses of PR3 (up to $25 \mu \mathrm{g} / \mathrm{ml}=860 \mathrm{nM}$ ) were unable to induce platelet activation measured as aggregation and serotonin release [13]. This finding is in line with our findings. However, in a later publication the same group failed to see any change in intracellular calcium in platelets with $600 \mathrm{nM}$ PR3 $(=17 \mu \mathrm{g} / \mathrm{ml})$ and they saw diminished capacity of thrombin to elicit a calcium response after pretreatment with PR3 [14]. A possible reason for the different results may be a difference in the preparation. PR3 is highly hydrophobic and detergents are necessary during preparation and storage, and our results highlight the possible influence of detergents in proteinase preparations. It should also be pointed out that the calcium signal we detected was modest and that we tested much lower concentrations of PR3, at which the presence of detergents was confirmed not to influence the results.

We found that both the low-molecular weight PR3 inhibitor PYDA and serum (presence of alpha1-antitrypsin) inhibited platelet shape change induced by PR3. Hence, we conclude that the proteolytic activity of PR3 is essential for its ability to modulate platelets. As mentioned above it has been shown that PR3 inhibits subsequent $\mathrm{Ca}^{2+}$ mobilization in platelets provoked by thrombin [14], and the underlying molecular mechanism was suggested to be PR3-induced proteolysis of PARs which removes the cleavage site for thrombin. Furthermore, PR3 can activate dendritic cells 
through cleavage of PAR2 but also disable PAR1 by proteolytic removal of the tethered ligand domain from the receptor [32]. Recently, it was demonstrated that PR3 can activate endothelial cells through non-canonical cleavage of PAR1 [33]. It is thus possible that PR3 modulates platelets via PAR cleavage and subsequent intracellular signaling. However, even when using flow cytometry to enable detection of subtle changes in platelet fibrinogen receptor activation, we found no evidence that PR3 could modulate platelet activation through the thrombin PAR1 or PAR4 receptors. Also, inhibition of PAR1 by SCH79797 showed no effect on PR3-induced shape change. Activation of platelet PAR1/4 by thrombin leads to powerful platelet activation and aggregation, while our findings point to a restrictive, modulating effect of PR3. Collectively, the present results point to a PAR $1 / 4$ independent mechanism underlying platelet shape change by PR3. In a recent publication, trypsin was shown to activate platelets enzymatically through a non-PAR-mediated mechanism, most probably through cleavage of another receptor. This activation was calcium-independent and involving the Src family kinases, as shown by its complete inhibition in the presence of $10 \mu \mathrm{M}$ PP2 [34]. In contrast to this, we found no evidence for a role of Src in platelet shape change induced by PR3. Furthermore, and opposite to our findings concerning PR3-mediated effects, trypsin did not provoke any calcium response in PAR4-deficient mice platelets. Taken together, it may be possible that PR3 can modulate platelets via PAR cleavage, but our flow cytometry experiments provide no support for a direct effect on PAR1 or PAR4, thus further studies are needed in order to establish the receptor responsible for the PR3-induced shape change. In conclusion, we suggest that the neutrophil protease PR3 is a direct modulator of human platelets and causes shape change through activation of the Rho/Rho kinase and $\mathrm{Ca}^{2+}$ signaling pathways. This finding highlights an additional mechanism in the 
complex interplay between neutrophils and platelets, which in turn might have an impact on haemostasis and inflammation. The physiological relevance and potential importance of PR3 in this interplay should be further investigated in future studies.

\section{Funding}

The study was supported by the Swedish Renal Foundation and the Asp Foundation is gratefully acknowledged.

\section{Conflict of interest}

The authors have no conflict of interest.

\section{Acknowledgements}

We would like to thank Wieslab $A B$ for purified human PR3 and Dr. Brice Korkmaz for providing the specific synthetic PR3 inhibitor and the specific PR3 substrate. 


\section{References}

[1] Rondina MT, Weyrich AS, Zimmerman GA. Platelets as cellular effectors of inflammation in vascular diseases. Circ Res 2013;112:1506-19.

[2] Engelmann B, Massberg S. Thrombosis as an intravascular effector of innate immunity. Nat Rev Immunol 2013;13:34-45.

[3] McDonald B, Urrutia R, Yipp BG, Jenne CN, Kubes P. Intravascular neutrophil extracellular traps capture bacteria from the bloodstream during sepsis. Cell Host Microbe 2012;12:324-33.

[4] Jennette JC, Falk RJ, Hu P, Xiao H. Pathogenesis of antineutrophil cytoplasmic autoantibody-associated small-vessel vasculitis. Annu Rev Pathol 2013;8:139-60.

[5] Halbwachs L, Lesavre P. Endothelium-neutrophil interactions in ANCA-associated diseases. Journal of the American Society of Nephrology : JASN 2012;23:1449-61.

[6] Phillipson M, Kubes P. The neutrophil in vascular inflammation. Nat Med 2011;17:1381-90.

[7] van der Geld YM, Limburg PC, Kallenberg CG. Proteinase 3, Wegener's autoantigen: from gene to antigen. J Leukoc Biol 2001;69:177-90.

[8] Campbell EJ, Campbell MA, Owen CA. Bioactive proteinase 3 on the cell surface of human neutrophils: quantification, catalytic activity, and susceptibility to inhibition. J Immunol 2000;165:3366-74.

[9] Halbwachs-Mecarelli L, Bessou G, Lesavre P, Lopez S, Witko-Sarsat V. Bimodal distribution of proteinase 3 (PR3) surface expression reflects a constitutive heterogeneity in the polymorphonuclear neutrophil pool. FEBS Lett 1995;374:29-33.

[10] Abdgawad M, Gunnarsson L, Bengtsson AA, Geborek P, Nilsson L, Segelmark M, Hellmark T. Elevated neutrophil membrane expression of proteinase 3 is dependent upon CD177 expression. Clin Exp Immunol 2010;161:89-97.

[11] Skold S, Zeberg L, Gullberg U, Olofsson T. Functional dissociation between proforms and mature forms of proteinase 3 , azurocidin, and granzyme $B$ in regulation of granulopoiesis. Exp Hematol 2002;30:689-96.

[12] Yang JJ, Preston GA, Pendergraft WF, Segelmark M, Heeringa P, Hogan SL, Jennette JC, Falk RJ. Internalization of proteinase 3 is concomitant with endothelial cell apoptosis and internalization of myeloperoxidase with generation of intracellular oxidants. Am J Pathol 2001;158:581-92.

[13] Renesto P, Halbwachs-Mecarelli L, Nusbaum P, Lesavre P, Chignard M. Proteinase 3. A neutrophil proteinase with activity on platelets. J Immunol 1994;152:4612-7.

[14] Renesto P, Si-Tahar M, Moniatte M, Balloy V, Van Dorsselaer A, Pidard D, Chignard M. Specific inhibition of thrombin-induced cell activation by the neutrophil proteinases elastase, cathepsin G, and proteinase 3: evidence for distinct cleavage sites within the aminoterminal domain of the thrombin receptor. Blood 1997;89:1944-53.

[15] Vu TK, Hung DT, Wheaton VI, Coughlin SR. Molecular cloning of a functional thrombin receptor reveals a novel proteolytic mechanism of receptor activation. Cell 1991;64:1057-68.

[16] Faruqi TR, Weiss EJ, Shapiro MJ, Huang W, Coughlin SR. Structure-function analysis of protease-activated receptor 4 tethered ligand peptides. Determinants of specificity and utility in assays of receptor function. J Biol Chem 2000;275:19728-34.

[17] Epinette C, Croix C, Jaquillard L, Marchand-Adam S, Kellenberger C, Lalmanach G, Cadene M, 
Viaud-Massuard MC, Gauthier F, Korkmaz B. A selective reversible azapeptide inhibitor of human neutrophil proteinase 3 derived from a high affinity FRET substrate. Biochem Pharmacol 2012;83:788-96.

[18] Lindahl TL, Festin R, Larsson A. Studies of fibrinogen binding to platelets by flow cytometry: an improved method for studies of platelet activation. Thrombosis and Haemostasis 1992;68:221-5.

[19] Fath MA, Wu X, Hileman RE, Linhardt RJ, Kashem MA, Nelson RM, Wright CD, Abraham WM. Interaction of secretory leukocyte protease inhibitor with heparin inhibits proteases involved in asthma. J Biol Chem 1998;273:13563-9.

[20] Koizumi M, Fujino A, Fukushima K, Kamimura T, Takimoto-Kamimura M. Complex of human neutrophil elastase with 1/2SLPI. J Synchrotron Radiat 2008;15:308-11.

[21] Otterdal K, Pedersen TM, Solum NO. Platelet shape change induced by the peptide YFLLRNP. Thromb Res 2001;103:411-20.

[22] Bauer M, Maschberger P, Quek L, Briddon SJ, Dash D, Weiss M, Watson SP, Siess W. Genetic and pharmacological analyses of involvement of Src-family, Syk and Btk tyrosine kinases in platelet shape change. Src-kinases mediate integrin alphallb beta3 inside-out signalling during shape change. Thromb Haemost 2001;85:331-40.

[23] Nilsson U, Svensson SP, Grenegard M. Synergistic activation of human platelets by lysophosphatidic acid and adrenaline. Haematologica 2002;87:730-9; discussion 9.

[24] Gunnarsson P, Fornander L, Pahlsson P, Grenegard M. Sialic acid residues play a pivotal role in alpha(1)-acid glycoprotein (AGP)-induced generation of reactive oxygen species in chemotactic peptide pre-activated neutrophil granulocytes. Inflamm Res 2010;59:89-95.

[25] Khandoga AL, Fujiwara Y, Goyal P, Pandey D, Tsukahara R, Bolen A, Guo H, Wilke N, Liu J, Valentine WJ, Durgam GG, Miller DD, Jiang G, Prestwich GD, Tigyi G, Siess W. Lysophosphatidic acid-induced platelet shape change revealed through LPA(1-5) receptor-selective probes and albumin. Platelets 2008;19:415-27.

[26] Steen VM, Holmsen H. Synergism between thrombin and epinephrine in human platelets: different dose-response relationships for aggregation and dense granule secretion. Thromb Haemost 1985;54:680-3.

[27] Grenegard M, Vretenbrant-Oberg K, Nylander M, Desilets S, Lindstrom EG, Larsson A, Ramstrom I, Ramstrom S, Lindahl TL. The ATP-gated P2X1 receptor plays a pivotal role in activation of aspirin-treated platelets by thrombin and epinephrine. J Biol Chem 2008;283:18493-504.

[28] Owen CA. Leukocyte cell surface proteinases: regulation of expression, functions, and mechanisms of surface localization. Int J Biochem Cell Biol 2008;40:1246-72.

[29] Bauer M, Retzer M, Wilde JI, Maschberger P, Essler M, Aepfelbacher M, Watson SP, Siess W. Dichotomous regulation of myosin phosphorylation and shape change by Rho-kinase and calcium in intact human platelets. Blood 1999;94:1665-72.

[30] Paul BZ, Daniel JL, Kunapuli SP. Platelet shape change is mediated by both calcium-dependent and -independent signaling pathways. Role of p160 Rho-associated coiled-coil-containing protein kinase in platelet shape change. J Biol Chem 1999;274:28293-300.

[31] Gunnarsson P, Levander L, Pahlsson P, Grenegard M. alpha(1)-acid glycoprotein (AGP)-induced platelet shape change involves the Rho/Rho kinase signalling pathway. Thromb Haemost 2009;102:694-703. 
[32] Shpacovitch VM, Seeliger S, Huber-Lang M, Balkow S, Feld M, Hollenberg MD, Sarma VJ, Ward PA, Strey A, Gerke V, Sommerhoff CP, Vergnolle N, Steinhoff M. Agonists of proteinase-activated receptor-2 affect transendothelial migration and apoptosis of human neutrophils. Exp Dermatol 2007;16:799-806.

[33] Mihara K, Ramachandran R, Renaux B, Saifeddine M, Hollenberg MD. Neutrophil elastase and proteinase-3 trigger G-protein biased signaling through proteinase activated receptor-1 (PAR1). J Biol Chem 2013;288:32979-90.

[34] Mao Y, Kunapuli SP. Trypsin causes platelet activation independently of known protease-activated receptors. Thromb Haemost 2013;110:1241-9. 


\section{Figure legends}

Figure 1: PR3 induces shape change in isolated human platelets. (A) Traces showing changes in light transmission in platelet suspensions treated with different doses of PR3 $(0-3.0 \mu \mathrm{g} / \mathrm{ml}=$ 0-100 $\mathrm{nM})$ and thrombin $(0.2 \mathrm{U} / \mathrm{ml})$. Arrows indicate addition of PR3 or thrombin. (B) Histogram quantifying the changes in transmission provoked by increased doses of PR3. The bars represent means \pm SEM ( $n=4)$. (C) Summarized effects of adrenaline on the PR3-induced decrease in light transmission. The data represent means \pm SEM, and statistical significance was tested using paired Student's t-test $(\star \star, p<0.01 ; n=4)$.

Figure 2: P-selectin expression and fibrinogen binding is unaffected by platelet pre-incubation with PR3. Isolated platelets pre-incubated for $10 \mathrm{~min}$ with or without PR3 $(0.6$ or $3 \mu \mathrm{g} / \mathrm{ml}=$ 20-100 nM) were activated by PAR1 or PAR4 activating peptides, or thrombin and the activation response, measured as P-selectin expression $(A)$ and fibrinogen binding $(B)$, was determined by flow cytometry. Data shown are means $\pm S E M, n=3$ (except for fibrinogen binding for thrombin at PR3 0 and $3 \mu \mathrm{g} / \mathrm{ml}$, where $\mathrm{n}=2$ ).

Figure 3: PR3 induced light transmission change is dependent on PR3 enzymatic activity. Rho-kinase activation and intracellular $\mathrm{Ca}^{2+}$ mobilization. PR3 induces pronounced Rho-kinase-dependent phosphorylation of MYPT1. 
(A) Histogram quantifying the change in light transmission provoked by PR3 $(0.6 \mu \mathrm{g} / \mathrm{ml}=20 \mathrm{nM})$ pre-incubated with control buffer, PYDA $(1 \mu \mathrm{M})$ or serum (1:1 volume ratio) for 30 minutes at $37^{\circ} \mathrm{C}$. Serum contains several protease inhibitors (e.g. alpha-1-antitrypsin) and PYDA is a low molecular weight protease inhibitor specific for PR3. The bars represent means \pm SEM, and statistical significance was tested using paired Student's t-test $(\star, p<0.05 ; n=3)$.

(B) Summarized effects of BAPTA/AM and Y-27632 on the PR3-induced decrease in light transmission. Short (5 minutes) pre-incubation with the calcium chelator BAPTA/AM (20 $\mu M)$, or Rho-kinase inhibitor Y-27632 $(20 \mu \mathrm{M})$, antagonized the PR3- $(0.6 \mu \mathrm{g} / \mathrm{ml}=20 \mathrm{nM})$ induced changes in platelets. Pre-incubation with a combination of Y-27632 $(20 \mu \mathrm{M})$ and BAPTA/AM $(20 \mu \mathrm{M})$ abolished the response. Bars represent means \pm SEM $(n=4)$, and $\star$ represent a statistical significant difference compared to control when using paired Student's t-test $(p<0.05)$. (C) PR3 $(0.6 \mu \mathrm{g} / \mathrm{ml})$ provoked a PYDA $(1 \mu \mathrm{M})$ - and Y-27632 (20 $\mu \mathrm{M})$-sensitive Thr696 phosphorylation on MYPT1 measured 10 seconds after stimulation in platelets. The bars represent means \pm SEM of densitometric values from western blots repeated thrice. The inset trace shows intracellular calcium mobilization in Fura-2-loaded platelet suspensions. PR3 $(0.3 \mu \mathrm{g} / \mathrm{ml}=10 \mathrm{nM})$ provoked a minor calcium rise in platelets. ANOVA with Dunnett's multiple comparison test was used to test the statistical significance of results from inhibitor-pre-incubated samples compared to the control (0.6 $\mu \mathrm{g} / \mathrm{ml}$ PR3 without inhibitors) $(\star, p<0.05 ; n=3)$.

(D) Original data from one western blot is shown under the bar graph. Y-27: Y-27632 (20 $\mu \mathrm{M})$; Thr: thrombin $(0.2 \mathrm{U} / \mathrm{ml})$. 
1.

A
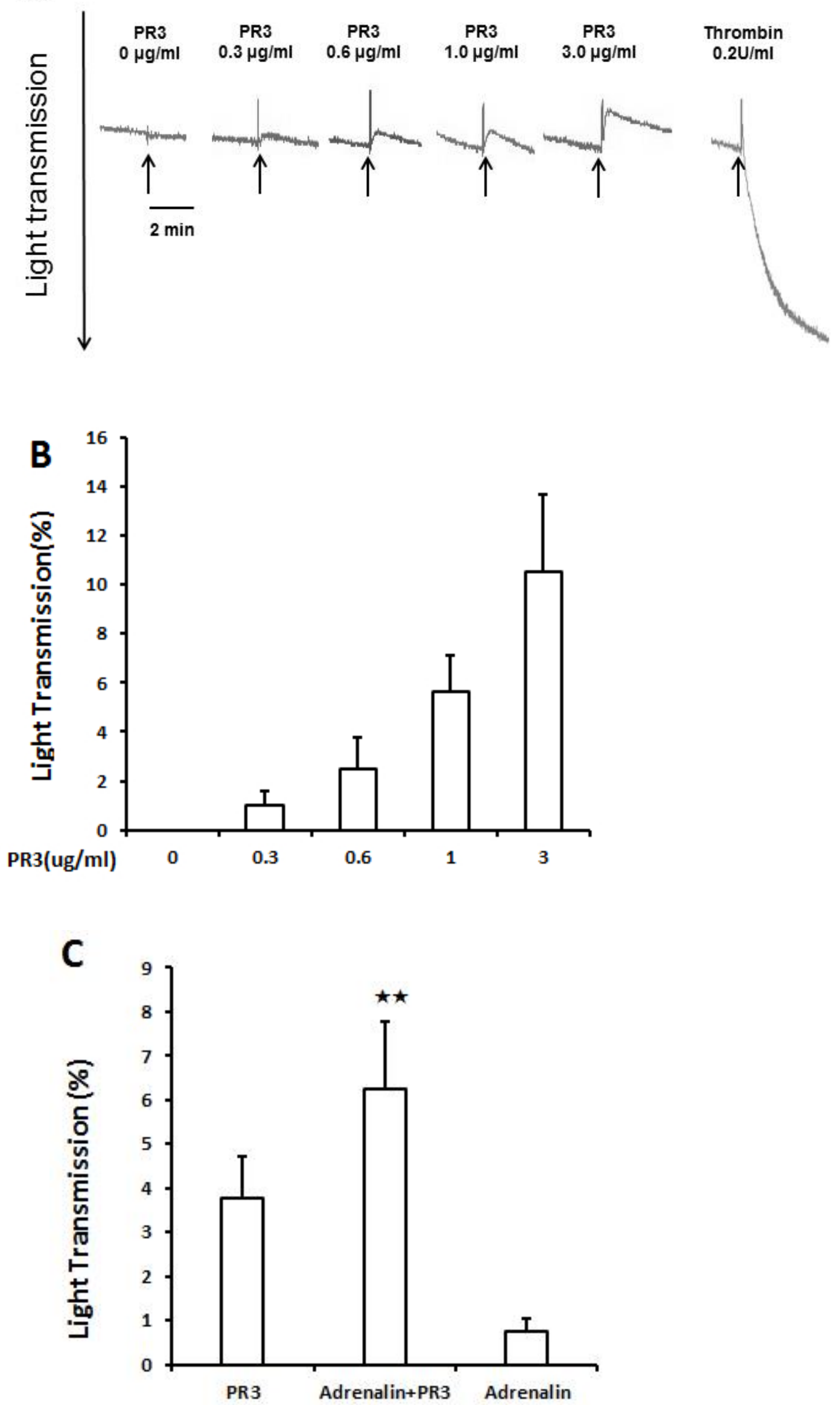
Figure 1: PR3 induces shape change in isolated human platelets. (A) Traces showing changes in light transmission in platelet suspensions treated with different doses of PR3 $(0-3.0 \mu \mathrm{g} / \mathrm{ml}=0-100 \mathrm{nM})$ and thrombin $(0.2 \mathrm{U} / \mathrm{ml})$. Arrows indicate addition of PR3 or thrombin. (B) Histogram quantifying the changes in transmission provoked by increased doses of PR3. The bars represent means \pm SEM $(n=4)$. (C) Summarized effects of adrenaline on the PR3-induced decrease in light transmission. The data represent means \pm SEM, and statistical significance was tested using paired Student's t-test ( $\star$ $\star, p<0.01 ; n=4)$.

2.

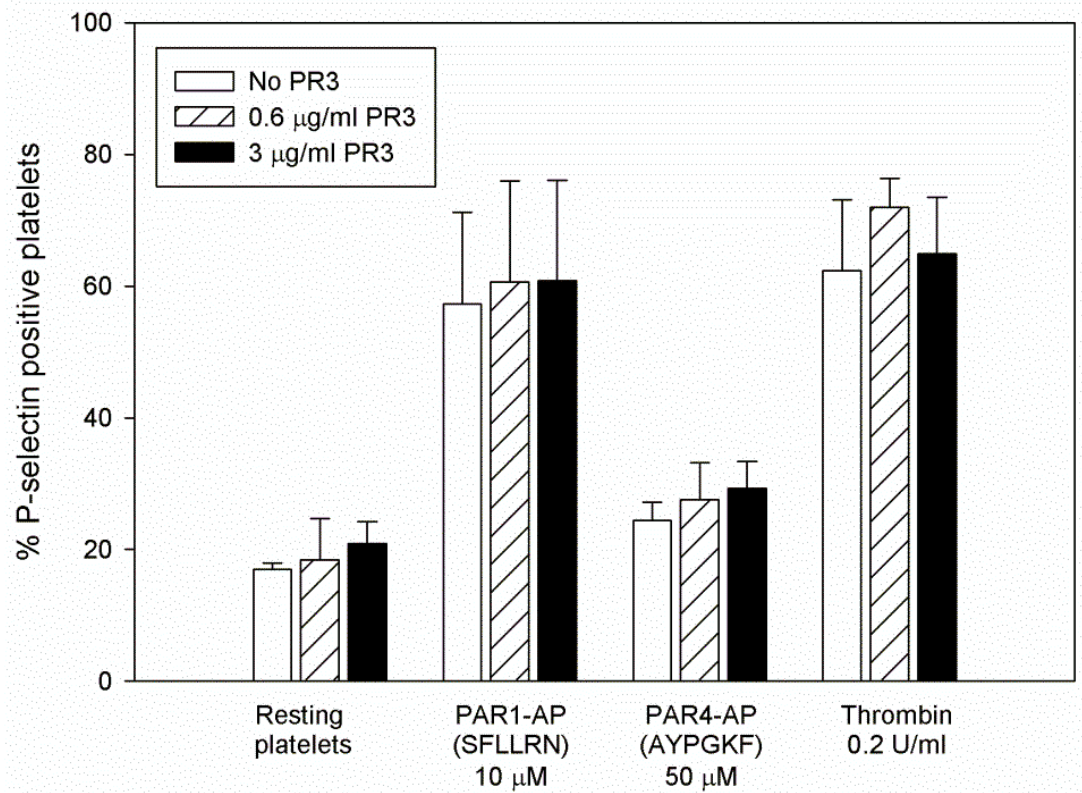




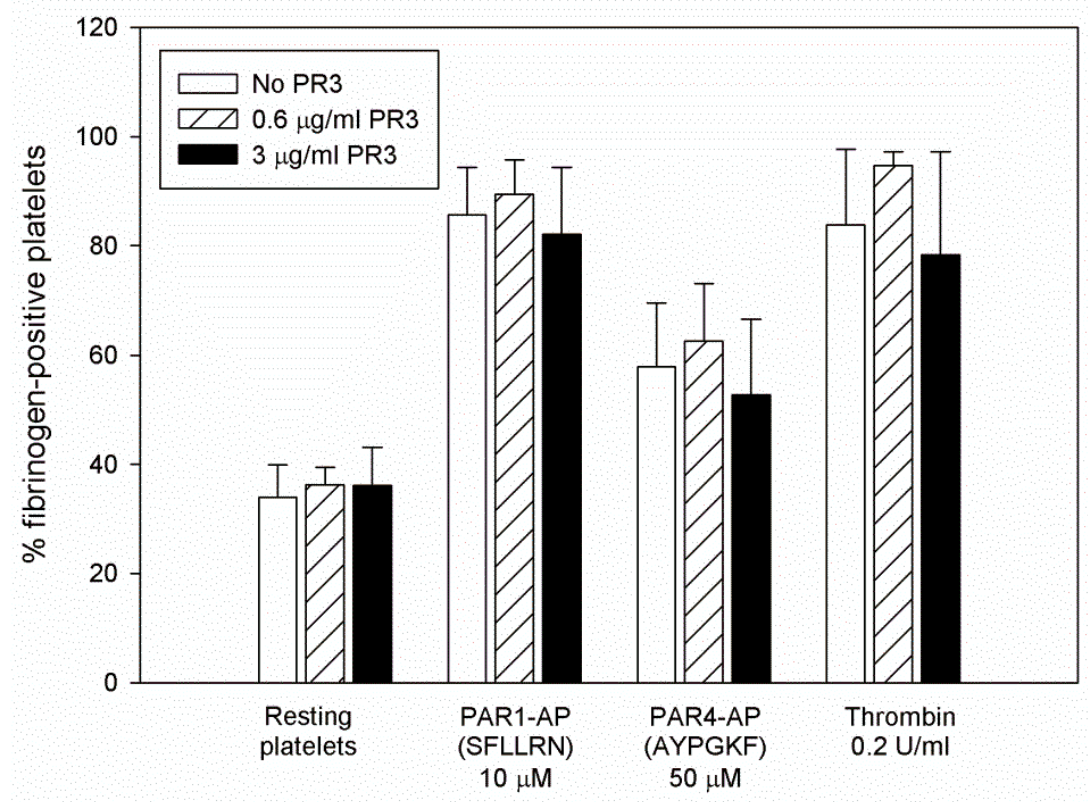

2

Figure 2: P-selectin expression and fibrinogen binding is unaffected by platelet pre-incubation with PR3. Isolated platelets pre-incubated for $10 \mathrm{~min}$ with or without PR3 $(0.6$ or $3 \mu \mathrm{g} / \mathrm{ml}=20-100 \mathrm{nM})$ were activated by PAR1 or PAR4 activating peptides, or thrombin and the activation response, measured as P-selectin expression (A) and fibrinogen binding (B), was determined by flow cytometry. Data shown are means $\pm \mathrm{SEM}, \mathrm{n}=3$ (except for fibrinogen binding for thrombin at PR3 0 and $3 \mu \mathrm{g} / \mathrm{ml}$, where $n=2$ ).

3. Figure 3: PR3 induced light transmission change is dependent on PR3 enzymatic activity, Rho-

kinase activation and intracellular $\mathrm{Ca}^{2+}$ mobilization. PR3 induces pronounced Rho-kinasedependent phosphorylation of MYPT1. 
A

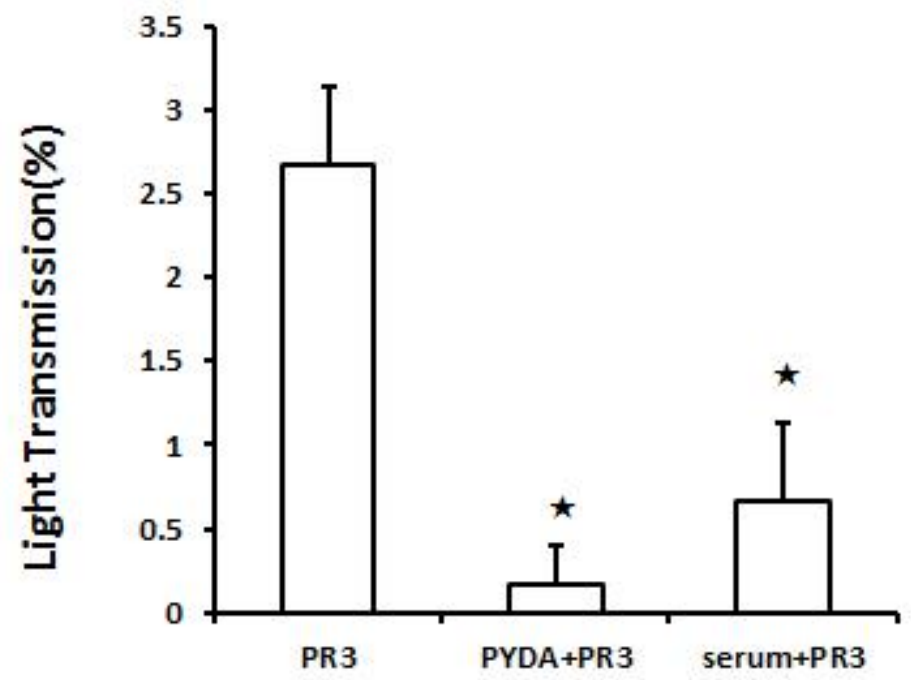

(A) Histogram quantifying the changes in light transmission provoked by PR3 $(0.6 \mu \mathrm{g} / \mathrm{ml}=20 \mathrm{nM})$ pre-incubated with control buffer, PYDA $(1 \mu \mathrm{M})$ or serum (1:1 volume ratio) for 30 minutes at $37^{\circ} \mathrm{C}$. Serum contains several protease inhibitors (e.g. alpha-1-antitrypsin) and PYDA is a low molecular weight protease inhibitor specific for PR3. The bars represent means \pm SEM, and statistical significance was tested using paired Student's t-test $(\star, p<0.05 ; n=3)$.

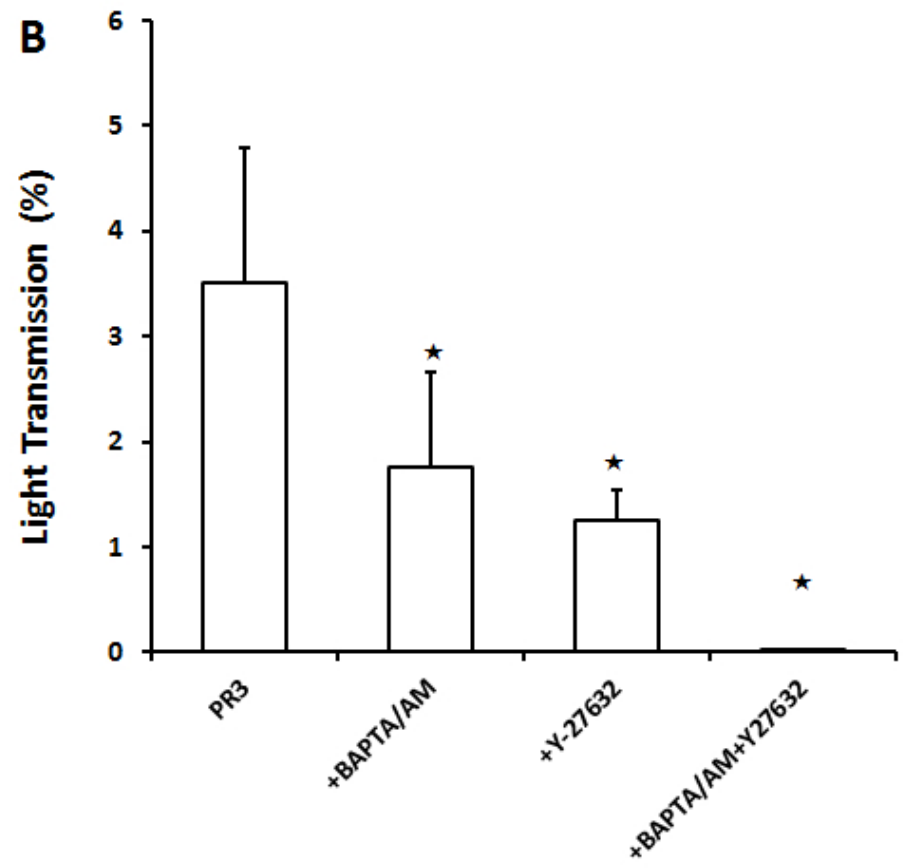


(B) Summarized effects of BAPTA/AM and Y-27632 on the PR3-induced decrease in light transmission. Short (5 minutes) pre-incubation with the calcium chelator BAPTA/AM (20 $\mu \mathrm{M})$, or Rho-kinase inhibitor Y-27632 $(20 \mu \mathrm{M})$, antagonized the PR3- $(0.6 \mu \mathrm{g} / \mathrm{ml}=20 \mathrm{nM})$ induced changes in platelets. Pre-incubation with a combination of Y-27632 $(20 \mu \mathrm{M})$ and BAPTA/AM $(20 \mu \mathrm{M})$ abolished the response. Bars represent means $\pm \operatorname{SEM}(n=4)$, and $\star$ represent a statistical significant difference compared to control when using paired Student's t-test $(p<0.05)$.

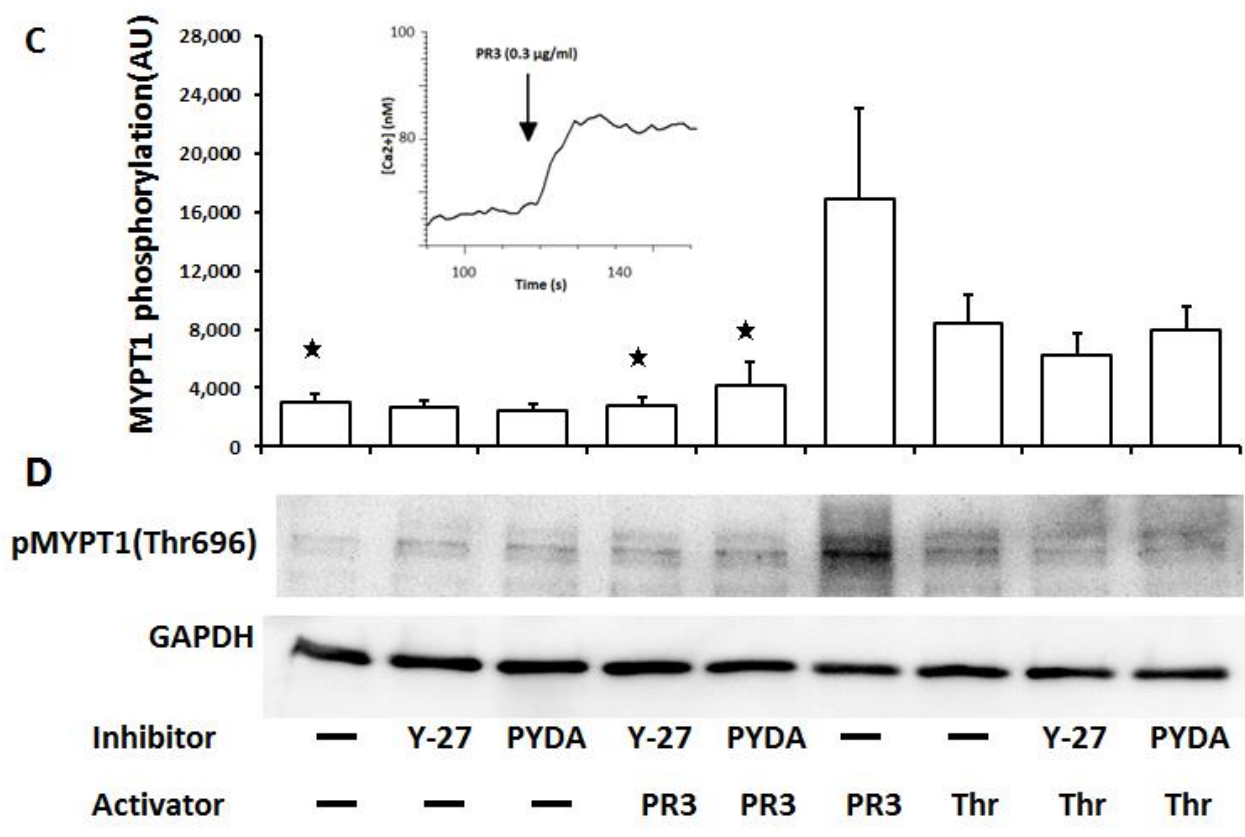

(C) PR3 $(0.6 \mu \mathrm{g} / \mathrm{ml})$ provoked a PYDA $(1 \mu \mathrm{M})$ - and Y-27632 $(20 \mu \mathrm{M})$-sensitive Thr696 phosphorylation on MYPT1 measured 10 seconds after stimulation in platelets. The bars represent means \pm SEM of densitometric values from western blots repeated thrice. The inset trace shows intracellular calcium mobilization in Fura-2-loaded platelet suspensions. PR3 $(0.3 \mu \mathrm{g} / \mathrm{ml}=10 \mathrm{nM})$ provoked a minor 
calcium rise in platelets. ANOVA with Dunnett's multiple comparison test was used to test the statistical significance of results from inhibitor-pre-incubated samples compared to the control (0.6 $\mu \mathrm{g} / \mathrm{ml}$ PR3 without inhibitors) ( $\star, p<0.05 ; n=3)$.

(D) Original data from one blot is shown under the bar graph. Y-27: Y-27632 (20 $\mu \mathrm{M})$; Thr: thrombin $(0.2 \mathrm{U} / \mathrm{ml})$ 